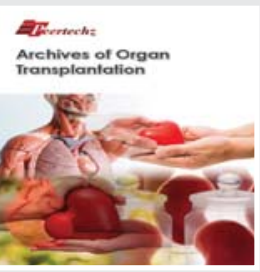

\title{
Clinical Group
}

\section{Archive of Organ Transplantation}

\section{Ana Theresa Guanaes Bonini, André Barros Albuquerque Esteves, Leonardo Figueiredo Camargo, Carla Feitosa do Valle, Gabriel Giollo Rivelli, Marcos Vinícius de Sousa and Marilda Mazzali*}

Division of Nephrology, Department of Medicine, School of Medical Sciences, University of CampinasDCM/FCM/UNICAMP, Rua Tessalia Vieira de Camargo, Brazil

Dates: Received: 15 December, 2016; Accepted: 18 March, 2017; Published: 22 March, 2017

*Corresponding author: Marilda Mazzali, Division of Nephrology, Department of Medicine, School of Medical Sciences, University of Campinas- DCM/FCM/UNICAMP, Rua Tessalia Vieira de Camargo, 126, Cidade Universitaria Zeferino Vaz, 13083-970- Campinas- Sao Paulo- Brazil, Tel: 55-19-35218204; Fax: 55-19-35218208; E-mail:marildamazzali@gmail.com

Keywords: Polyomavirus; mTOR inhibitor; Renal transplantation

https://www.peertechz.com

\section{Case Report \\ Therapy with mTOR Inhibitors in Polyomavirus Allograft Nephropathy (PVAN): A Five Year Follow Up}

\section{Abstract}

Polyomavirus nephropathy (PVAN) has a negative impact on renal allograft survival. Therapy options include reduction of immunosuppression and antiviral drugs.

Aim: Evaluate the effect ofmTORi based immunosuppression on PVAN.

Methods: Cross-sectional cohort of 21 renaltransplant recipients with PVAN. Initial immunosuppression based on MPA/tacrolimus was changed to $\mathrm{mTOR} /$ steroids at diagnosis, if urine protein/creatinine ratio $<0.5 \mathrm{~g} / \mathrm{l}$. Patients weremonitored by urine cytology, qualitative PCR in peripheral blood, serum creatinine andprotein/creatinine ratio.

Results: PVAN was suspected $14.3 \pm 19.3$ months post-transplant, by thepresence of decoy cells in serial urine cytology. At this point, serum creatinine was $1.4 \pm 0.5 \mathrm{mg} / \mathrm{dL}$, through levels of tacrolimus (TAC) was $8.6 \pm 3.5 \mathrm{ng} / \mathrm{dL}$. TAC dose was reduced (through level $6.8 \pm 2.8 \mathrm{ng} / \mathrm{dL}$ ). However, in presence of persistent viruria and allograft dysfunction (creatinine $2.5 \pm 0.7 \mathrm{mg} / \mathrm{dL}$ ), a biopsy was performed $30.0 \pm 18.1$ months post-transplant, with the final diagnosis of PVAN stage 2. MPA and TAC were withdrawn and immunosuppressive therapy maintained with mTORi (sirolimus or everolimus) plus steroids. No rejection episodes were observed. In a 5-year follow up, 10/21 (47.6\%) grafts were lost due progression of PVAN. Risk factors for graft loss were higher creatinine at first viruria $(1.7 \pm 0.7$ versus $1.4 \pm 0.4 \mathrm{mg} / \mathrm{dl}, \mathrm{p}<0.05)$ or at biopsy ( $3.1 \pm 0.6$ versus $2.3 \pm 0.7 \mathrm{mg} / \mathrm{dl}$ ), compared to group with a functioning graft after 5 years. In the latter group, after 70 months of follow-up, renal function remained stable (creatinine $2.0 \pm 0.5 \mathrm{mg} / \mathrm{dl}$ ); with negative viruria 16 weeks post mTORi.

Conclusion: In this series, the change of immunosuppression to mTORi and prednisone was safe with cleared viruria onaverage 16 weeks after conversion. In patients with earlier renal biopsy and with better renal function, this strategy preserved the allograft function.

\section{Introduction}

Polyomavirus allograft nephropathy (PVAN) is an important post-transplant complication. Despiteits low incidence, around $5 \%$, graft loss occurs in about $50 \%$ of cases [1]. In established PVAN (stage B), reduction in immunosuppressive therapy is considered as a safe strategy, in order to retard graft loss. However, the best approach remains controversial. While some groups suggest reduction of mycophenolate doses, others consider calcineurin inhibitors withdrawal or converting therapy to mTOR inhibitors or azathioprine [2].

Experimental data showed that Polyomavirus activates mTOR pathway in epithelial tubular cells. In Polyomavirus infected tubular cells culture, sirolimus and/or leflunomide reduced the expression of BKvirus large $\mathrm{T}$ antigen, suppressing the infection [3].
Based on these data, we hypothetized that early changes in immunosuppression to proliferation signal inhibitors (PSImTORi) in renal transplant patients with viruria or viremia could have a protective effect on the progression of PVAN. Local protocol consists in routine screening for Polyomavirus infection by sequential viruria (urine cytology) and conversion to mTORi (sirolimus or everolimus) at histologic confirmation of PVAN. The aim of this study was to evaluate the safety and efficacy of converting therapy to mTORi in renal transplant patients with PVAN.

\section{Patients and Methods}

From the renal transplant database, all patients with PVAN diagnosis were selected, and medical records analyzed for inclusion and exclusion criteria. Inclusion criteria:

a) Recipients from isolated kidney. 
b) Age $>18$ years old at transplant.

c) Diagnosis of PVAN.

d) Converting therapy to mTOR inhibitor. Local Ethics Committee approved the protocol.

Routine screening of Polyomavirus: all renal transplant recipients have a sequential viruria screening (decoy cells in urine cytology), in a regular interval within first 3 years posttransplant is classified according to Banff criteria [4]. Cases of persistent viruria and allograft biopsy without viral inclusions were defined as presumed PVAN. When viral inclusions were observed, cases were classified as confirmed PVAN. Immunosuppressive therapy after PVAN diagnosis: withdrawal of calcineurin inhibitor and MPA and introduction of mTORi if urine protein/creatinine ratio $<0.5$. Steroids are maintained at same dose. For patients of high immunological risk, MPA dose is tapered or azathioprine or cyclosporine added to mTORi therapy. Sequential biopsies performed if graft dysfunction progresses. Data analysis: donor source, primary renal disease, initial mmunosuppressive protocol, interval from transplant to PVAN diagnosis, acute rejection episodes, serum creatinine, protein/creatinine ratio and persistence of viruria/viremia. Study end points: graft loss or patient loss (Figures 1,2).

For analysis, patients were divided in 3 groups, according to viruria after converting to mTORi: persistent $(n=5)$, negative $(n=10)$ or recurrent $(n=6)$.

\section{Statistical analysis}

data are compared by Anova and Bonferroni tests. Statistical significance was considered if $\mathrm{p}<0.05$.

\section{Results}

Twenty-one patients fulfill the inclusion criteria, and were converted to mTOR inhibitor (sirolimus) at diagnosis of PVAN. Mean age of study group was $42.1 \pm 11.3$ years old. The majority of patients were male $(85.7 \%)$, recipients from a kidney from a deceased donor $(76.1 \%)$, with mean cold ischemia time of 15.6 \pm 5.7 hours. Incidence of delayed graft function was $38.1 \%$, and $14.3 \%$ patients had CMV infection. HLA matching was $1.2 \pm 0.8$ (AB locus) and $1.6 \pm 0.5$ (DR locus). PVAN was suspected by first viruria $14.3 \pm 19.3$ months post-transplant, with a serum creatinine of $1.4 \pm 0.5 \mathrm{mg} / \mathrm{dL}$. Renal biopsy was performed after $30 \pm 18.1$ months, with serum creatinine of $2.5 \pm 0.7 \mathrm{mg} / \mathrm{dL}$. In sixteen patients $(76,2 \%)$, viruria turned negative 4 months after converting to mTOR inhibitor. However, in 6 cases, decoy cells recurred. In recurrent group compared to persistent or negative ones, despite comparable renal function. Recurrent group has a late indication for biopsy, probably because of the recurrent pattern of viruria. Analysis of the 3 different groups showed that at diagnosis there was no difference between responders and no responders to mTORi therapy. However, in the persistent and recurrent viruria groups, graft loss occurred in $80 \%$ of cases, earlier in the persistent ones $(34.1 \pm 16.0$ vs. $61.3 \pm 14.2$ months, persistent vs. recurrent, $\mathrm{p}<0.05)$. In negative viruria group, only one graft was lost $(10 \%)$ after 5 years of follow up (Table 1).

\section{Discussion}

Polyomavirus has a negative impact on renal graft function, with a higher rate of graft loss [1]. Despite progress in diagnosis and classification of severity of PVAN, there is no consensus about therapy. A metanalysis of PVAN therapy concluded that the only benefit was in reducing immunosuppressive therapy [2]. However, the best protocol is not a consensus. While some groups suggest to avoid mycophenolate, others consider avoid tacrolimus or add mTOR inhibitors to therapy [2]. Analysis of clinical trials with mTORi showed a lower incidence of viral infections, for both cytomegalovirus and Polyomavirus $[5,6]$. Also, data from cell culture showed that mTORi (sirolimus) inhibits BKvirus large $\mathrm{T}$ antigen expression [3]. Based on these data, we designed aprotocol for PVAN therapy. When BK virus infection was suspected, by detecting decoy cells in

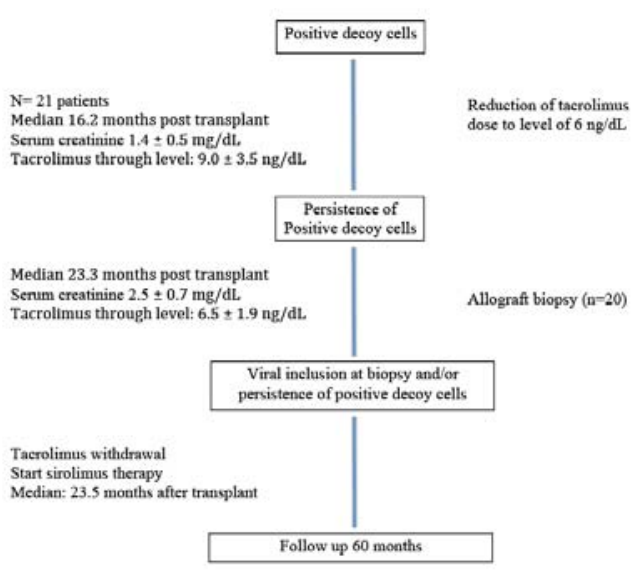

Figure 1: Study protocol design.
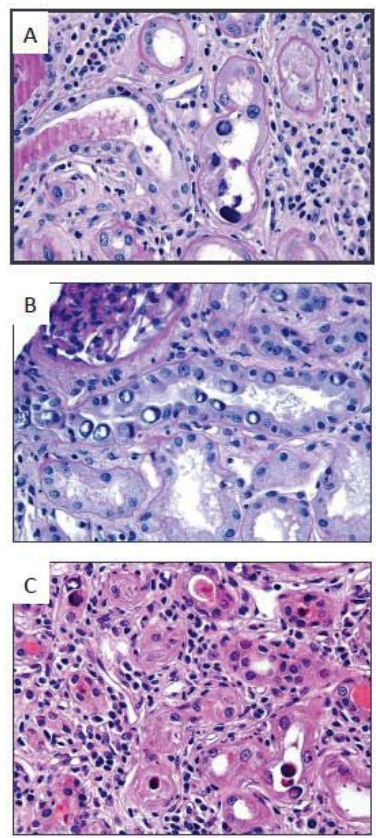

Figure 2: Polyomavirus nephropathy. [A] PVAN grade A. Viral inclusions in epithelial tubular cells, medullar area. PAS staining, 400x magnification. [B] PVAN grade B: viral inclusions in tubular cells, renal cortex. PAS staining, 400x magnification. [C]. PVAN grade C. Interstitial fibrosis and inflammation. Epithelial cell with viral inclusion in tubular lumen. HE staining, 400x magnification. 
Table 1: Patients characteristics according to viruria after converting to mTOR therapy.

\begin{tabular}{|c|c|c|c|}
\hline & Negative & Recurrent & Persistent \\
\hline Number of cases & 10 & 6 & 5 \\
\hline Age (Years old) & $39.1 \pm 11.8$ * & $46.5 \pm 12.8$ & $42.8 \pm 8.6$ \\
\hline Gender (male: female) & 10:0 & $3: 3$ & $5: 0$ \\
\hline Creatinine at viruria $(\mathrm{mg} / \mathrm{dL})$ & $1.4 \pm 0.5$ & $1.3 \pm 0.6$ & $1.8 \pm 0.7^{\star}$ \\
\hline Creatinine at biopsy (mg/dL) & $2.5 \pm 0.9$ & $2.7 \pm 0.7$ & $2.5 \pm 0.2$ \\
\hline Creatinine at conversion (mg/dL) & $2.6 \pm 1.4$ & $2.8 \pm 1.1$ & $2.7 \pm 0.7$ \\
\hline Tacrolimus level at viruria (ng/dL) & $9.7 \pm 3.4$ & $9.5 \pm 4.8$ & $7.3 \pm 1.3^{\star}$ \\
\hline $\begin{array}{l}\text { Tacrolimus level at diagnosis } \\
\text { (ng/dl) }\end{array}$ & $6.9 \pm 1.7$ & $5.8 \pm 1.3$ & $6.8 \pm 2.9$ \\
\hline $\begin{array}{l}\text { Time to biopsy after transplant } \\
\text { (months) }\end{array}$ & $28.4 \pm 15.8$ & $35.7 \pm 23.9 *$ & $25.9 \pm 16.6$ \\
\hline $\begin{array}{l}\text { Length from viruria to mTOR } \\
\text { (months) }\end{array}$ & $16.0 \pm 12.5$ & $10.7 \pm 8.3$ & $11.9 \pm 21.4$ \\
\hline $\begin{array}{l}\text { Length from diagnosis to mTOR } \\
\text { (months) }\end{array}$ & $3.7 \pm 7.9 *$ & $0.7 \pm 0.3$ & $1.2 \pm 1.7$ \\
\hline $\begin{array}{l}\text { Length from transplant to mTOR } \\
\text { (months) }\end{array}$ & $31.6 \pm 27.5^{\star}$ & $25.3 \pm 6.2$ & $26.1 \pm 15.4$ \\
\hline $\begin{array}{l}\text { Length for negative viruria } \\
\text { (months) }\end{array}$ & $5.1 \pm 4.8$ & $2.9 \pm 3.1$ & n.a. \\
\hline Graft loss & $1(10 \%)$ & $5(83.3 \%)$ & $4(80 \%)$ \\
\hline $\begin{array}{l}\text { Length from diagnosis to graft loss } \\
\text { (months) }\end{array}$ & 58 & $61 \pm 14$ & $34.1 \pm 16^{*}$ \\
\hline
\end{tabular}

urine cytology, tacrolimus dose was reduced in 50\%. If viruria persists and PVAN was observed at biopsy, tacrolimus and MPA were withdrawn and replaced by sirolimus and steroids. When the whole group was analyzed, data was promising. However, in a long term follow up graft loss was $47.6 \%$, comparable to previous reports. In order to identify responders (negative viruria) and nonresponders (persistent or recurrent analysis) we decided for a sub group study. The first interesting finding was that a group of patients $(16 / 21)$ had a rapid decline in viruria after converting to mTORi. We were not able to identify in demographic or transplant related data, risk factors for this pattern. However, during follow up, part of the responder group (6/16) had recurrent viruria, with need for late allograft biopsy. Long-term analysis showed that graft loss was comparable between patients with persistent or recurrent viruria, in about $80 \%$, suggesting that the changes in immunosuppression were not efficient to control PVAN [7].
However, patients with negative viruria had a better prognosis, with graft loss of $10 \%$ and a stable graft function after 5 years of PVAN diagnosis. Unfortunately, at diagnosis, there is no clear data that suggests the rate of progression of PVAN or the response to mTORi therapy. In conclusion, therapy with mTOR inhibitors was safe in patients with PVAN. However, its efficacy was of $50 \%$ in the whole group. Patients with rapid response to mTORi, with negative viruria, should be closely monitored, as recurrence of viruria can occur, with a high risk for graft loss. Persistence of negative viruria was associated with a better graft survival.

\section{References}

1. Hirsch $\mathrm{HH}$, Brennan DC, Drachemberg CB, Ginevri F, Gordon J, et al (2005) Polyomavirus associated nephropathy in renal transplantation: Interdisciplinary Analyses and recommendations. Transplantation 79: 1277. Link: https://goo.gl/eeWUIM

2. Johnston O, Jaswal D, Gill JS, Doucette S, Fergusson DA, et al. (2010) Treatment of Polyomavirus infection in kidney transplant recipients: a systematic review. Transplantation 89: 1057-1070. Link: https://goo.gl/OQYjln

3. Liacini A, Seamone ME, Muruve, Tibbles LA (2010) Anti BK virus mechanism of sirolimus and leflunomide alone and in combination: toward a new therapy for BK virus infection. Transplantation 90: 1450. Link: https://goo.gl/c950ap

4. Matsutani K, Shapiro R, Basu A, Tan H, Wijkstrom M, et al. (2012) The Banff 2009 Working proposal for Polyomavirus Nephropathy: a critical evaluation of its utility as a determinant of clinical outcome. Am J Transplant 12: 907918. Link: https://goo.gl/QWtrd3

5. Benavides CA, Pollard VB, Mauiyyedi S, Podder H, Knight R, et al. (2007) BK Virus-Associated Nephropathy in Sirolimus-Treated Renal Transplant Patients: Incidence, Course, and Clinical Outcomes. Transplantation 84: 8388. Link: https://goo.gl/EfqqEx

6. Suwelack B, Malyar V, Koch M, Sester M, Sommerer C (2012) The influence of immunosuppressive agents on BK virus risk following kidney transplantation, and implications for choice regimen. Transplant Rev 26: 201-211. Link: https://goo.gl/x0K2zA

7. Babel N, Fendt J, Karaivanov S, Bold G, Arnold S, et al. (2009) Sustained BK viruria as an early marker for the development of BKV-associated nephropathy: Analysis of 4128 urine and serum samples. Transplantation 88 89-95. Link: https://goo.gl/Fvk3qZ 